\title{
Health Perception and Behaviors in Adults With Bronchiectasis
}

\author{
Wei-jie Guan, Jing-jing Yuan, Hui-min Li, Yan Huang, Chun-lan Chen, Yong-hua Gao, \\ Rong-chang Chen, and Nan-shan Zhong
}

\begin{abstract}
BACKGROUND: Bronchiectasis is a chronic debilitating suppurative disease that significantly impacts quality of life. Clinical outcomes like exacerbations, are usually physician centered; however, the patients' experience, health-related behaviors, and expectations have frequently been neglected. In addition, patients' health perceptions may be influenced by their culture. OBJECTIVE: To determine the health perception and behavior in adults with bronchiectasis. METHODS: We performed semi-directive interviews, which were audiotaped, with 60 adults with bronchiectasis between April 2016 and December 2016. Our interview focused on issues related to symptom perception, access to health-care resources and patient-physician communication, medication adherence, outcomes and expectations, quality of life, and social relationships. RESULTS: The subjects with bronchiectasis developed varying patterns of symptom perception (ranging from highly distressing to barely disturbing) and had conflicting opinions on whether and when they should seek health-care services (ranging from active consultations to being totally passive or resistant to seek health care). We observed certain discrepancies between symptom perception and health-related behaviors. Overall, medication adherence was suboptimal, but the subjects were willing to participate in clinical trials and receive complementary alternative medications despite concerns regarding adverse effects of prolonged treatment. There were concerns about the adverse effects of bronchiectasis on fertility and infectiousness to others, although most subjects disregarded these issues. CONCLUSIONS: The diverse symptom perception and health-related behaviors highlighted the need for evaluation and intervention in bronchiectasis. These findings will provide rationales for refining future health care through comprehensive (particularly psychological) interventions worldwide. Key words: bronchiectasis; perception; medication adherence; quality of life; cost of illness. [Respir Care 2019;64(4):462-472. (C) 2019 Daedalus Enterprises]
\end{abstract}

\section{Introduction}

Bronchiectasis is not an orphan lung disease. ${ }^{1-6}$ The most prominent symptoms of bronchiectasis are chronic

Drs Guan, Yuan, Li, Huang, Chun-lan Chen, Rong-chang Chen, and Zhong are affiliated with State Key Laboratory of Respiratory Disease, National Clinical Research Center for Respiratory Disease, Guangzhou Institute of Respiratory Health, First Affiliated Hospital of Guangzhou Medical University, Guangzhou Medical University, Guangzhou, Guangdong, China. Dr Guan is affiliated with Sino-French Hoffmann Institute, Guangzhou Medical University, Guangzhou, China. Dr Gao is affiliated with First Affiliated Hospital of Zhengzhou University, Zhengzhou, China.

Dr Guan declared that he has received Pearl River S\&T Nova Program of Guangzhou No. 201710010097, Guangdong Province Universities and Colleges Pearl River Scholar Funded Scheme 2017, and National Natural Science Foundation (No. 81870003). Dr Gao declared that he has received National Natural Science Foundation No. 81500006. Drs Zhong cough and production of mucopurulent or purulent sputum, followed by hemoptysis, fatigue, or dyspnea. Recurrent airway infections can result in exacerbations associated with increased health-care costs and poor quality of life. Despite greater awareness and improvement in research efforts, the management of bronchiectasis has been

and Chen declared that they had received Changjiang Scholars and Innovative Research Team in University ITR0961, The National Key Technology R\&D Program of the 12th National Five-year Development Plan 2012BAI05B01 and National Key Scientific \& Technology Support Program: Collaborative innovation of Clinical Research for chronic obstructive pulmonary disease and lung cancer No. 2013BAI09B09. None of the funding sources had any role with the study. The remaining authors have disclosed no conflicts of interest.

Supplementary material related to this paper is available at http:// www.rcjournal.com. 
hampered by a lack of understanding of the pathogenesis and effective medications. The mortality remains considerably high. ${ }^{4,7,8}$ Globally, management of bronchiectasis is multidimensional, ${ }^{7,9}$ but the evidence to guide therapeutic decisions remains scarce. This is particularly true in China where the etiologic spectra remain largely unclear, although cystic fibrosis is unlikely the common underlying cause.

Bronchiectasis confers significant adverse impacts. Nocturnal productive cough impairs sleep quality, ${ }^{10}$ which results in anxiety and depression ${ }^{11}$ associated with impaired quality of life. ${ }^{10}$ Frequent exacerbation is a risk factor for mortality. ${ }^{12}$ Although clinical trials have mostly focused on well-established end points (ie, exacerbations, ${ }^{13,14}$ bacterial load, ${ }^{15}$ and airway inflammation ${ }^{16}$ ), many important patient-centered outcomes have frequently been neglected. Identification of these critical issues may complement current disease management. A lack of information and selfefficacy is an obstacle to self-management of bronchiectasis. ${ }^{17}$ The balance between barriers and motivation can affect adherence to treatment. ${ }^{18}$ Social embarrassment, sleep disturbance, anxiety, and modification of daily and future activities may lead to significantly impaired quality of life in individuals with bronchiectasis. ${ }^{19}$ In addition, information deficits may constrain self-management in individuals with bronchiectasis. ${ }^{20}$ Nonetheless, little is known regarding health perception and behaviors in patients with bronchiectasis, apart from self-management in developing countries where the cultural background may be different.

Bronchiectasis management in China has not been well documented. There have been notable differences in the health-care system compared with developed countries. In China, the lack of a system for triage to different levels of care has been attributed to direct consultation in tertiary hospitals. The immense work load has resulted in burnout of health-care staff because they do not have enough time to be engaged in patient health-care education. Physicians in China are often not as respected as in other countries. Despite progress in health-care reform, health education remains largely deficient, particularly in rural areas. Patients seek health care inconsistently, and their adherence to medication or treatment may be suboptimal. In many primary health-care settings, traditional Chinese medicine remains the preferred therapeutic option. A better understanding of health perception and behavior could be

Correspondence: Rong-chang Chen MD, State Key Laboratory of Respiratory Disease, National Clinical Research Center for Respiratory Disease, Guangzhou Institute of Respiratory Health, First Affiliated Hospital of Guangzhou Medical University, 151 Yanjiang Road, Guangzhou, Guangdong, China 510120. E-mail: chenrc@vip.163.com.

DOI: $10.4187 /$ respcare.06394

\section{QUICK LOOK}

\section{Current knowledge}

Bronchiectasis is a chronic debilitating airway disease that contributes to significantly impaired quality of life. Health perception and behaviors, the mostly neglected aspects of bronchiectasis management, seemed to be highly diversified in recent literature reports.

\section{What this paper contributes to our knowledge}

Subjects with bronchiectasis demonstrated diverse symptom perception and health-related behaviors. Improved knowledge regarding symptom perception and health-related behaviors addresses the clinical need to more comprehensively assess and manage bronchiectasis. This research is important given the previously neglected aspects of patient evaluation (particularly quality of life), which usual center on the effectiveness of conventional treatment.

achieved via improved communication with patients with bronchiectasis. We conducted interviews that specifically focused on perception and behaviors in subjects with bronchiectasis. We highlighted neglected, but important, issues related to bronchiectasis: impact on fertility, traditional Chinese medicine, expectations of development of novel medications, and willingness to participate in clinical trials.

\section{Methods}

\section{Subject Recruitment}

Sixty subjects with bronchiectasis were recruited between April and December 2016. To represent real-world practice, we selected a convenience sample from the outpatient clinics of The First Affiliated Hospital of Guangzhou Medical University. Eligible patients were ages $18-75$ y and had bronchiectasis diagnosed by high-resolution computed tomography within the previous 12 months. ${ }^{16}$ Exclusion criteria were patients with language barriers and participation in clinical trials within the past 3 months. Disease severity was assessed with the Bronchiectasis Severity Index $(0-4,5-8$, and $\geq 9$ points denoted mild, moderate, and severe bronchiectasis, respectively). The ethics committee of The First Affiliated Hospital of Guangzhou Medical University gave approval. The subjects gave written and verbal consent before the interview. The flow chart of subject recruitment is shown in Figure 1. 


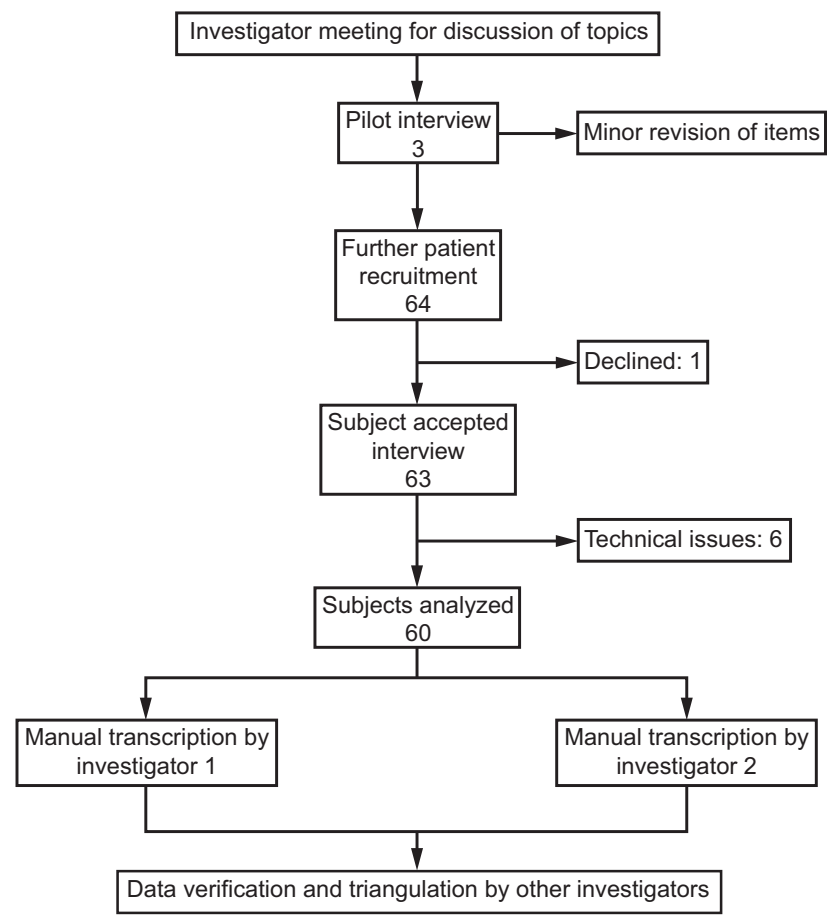

Fig. 1. Flow chart. Technical issues included both complete and partial loss of audio files.

\section{Study Design and Data Generation and Analysis}

An investigators' meeting (all members) was held to discuss key questions related to subjects' perception and management of bronchiectasis and, subsequently, formulated the scheduled interviews. The research nurse (HML) invited consecutive patients to participate, whereas 4 investigators (WJG, JJY, YH, CLC) organized interviews. Willing subjects received an informational letter and selected an available time for participation. A structured schedule of given topics was used to guide the semi-directive interview. Interviews were conducted in a private room, with audio recording. The subjects were encouraged to communicate freely by using Mandarin or Cantonese), and each interview lasted between 30 and $60 \mathrm{~min}$.

Contents of the interview were recorded for transcription of subject's statements into an electronic database. Four pre-determined categories were formed: (1) symptom perception; (2) access to health-care resources and patientphysician communication; (3) medication adherence, outcomes, and expectations; and (4) quality of life and social relationships. We performed a pilot interview with 3 subjects, followed by a debriefing, which entailed identification of norms and conflicting viewpoints. We made minor revisions after analysis of audio records by adding a question regarding the subject's willingness to participate in clinical trials (to investigate whether the subjects would deem participation in clinical trials acceptable according to Chinese culture and their own beliefs).
Subsequent interviews were performed according to the modified topics (Table 1). After familiarization with the audio recordings and a notes review, an investigator (WJG) manually transcribed the records, followed by selective coding. We compared responses across individuals, followed by data rearrangement and framework development into 4 main categories. We investigated the subjects' willingness to seek health care (not every subject initially sought consultation in primary facilities or be bound to a fixed tertiary hospital), subjects' self-assessment of treatment outcomes of traditional Chinese medicine, adverse effects of medications, and the impact of bronchiectasis on quality of life not disclosed previously (eg, fertility, exercise). Matrices were generated to demonstrate the main themes. Other investigators (JJY, HML, YH, CLC, YHG, RCC and NSZ) verified the main and subcategories via a follow-up questionnaire. One investigator (WJG) translated records into English for manuscript drafting and performed statistical analysis by using GraphPad Prism 5.0 (GraphPad, La Jolla, California). Transcripts that represented common summary comments and/or opinions or that contained sufficient information and/or interpretation for the statements are presented.

\section{Results}

\section{Subject Characteristics}

Sixty subjects were finally included for data analysis. The mean age was $49.1 \mathrm{y}, 56.7 \%$ females, and $91.7 \%$ neversmokers. The mean Bronchiectasis Severity Index was 5.9 (Table 2). Categories and subcategories are shown in the supplementary material (see the supplementary materials at http:// www.rcjournal.com). Representative responses to interview questions are presented in Tables 3-6.

\section{Symptom Perception}

Recurrent cough, followed by sputum production, was the most bothersome symptom.

- "Only when it [the sputum] was coughed up that I would feel comfortable. . . . I would immediately cough it out when I've got the phlegm" (subject no. 23: female, age $50 \mathrm{y})$.

Most subjects had experienced hemoptysis; however, attitudes toward management were conflicting. Most patients actively sought health care in the case of hemoptysis.

- "Coughing up blood was sometimes troublesome. . . I would always immediately go to the hospital for medication once I coughed up blood" (subject no. 43: male, age $35 \mathrm{y})$. 
Table 1. Interview Contents for Adults With Bronchiectasis

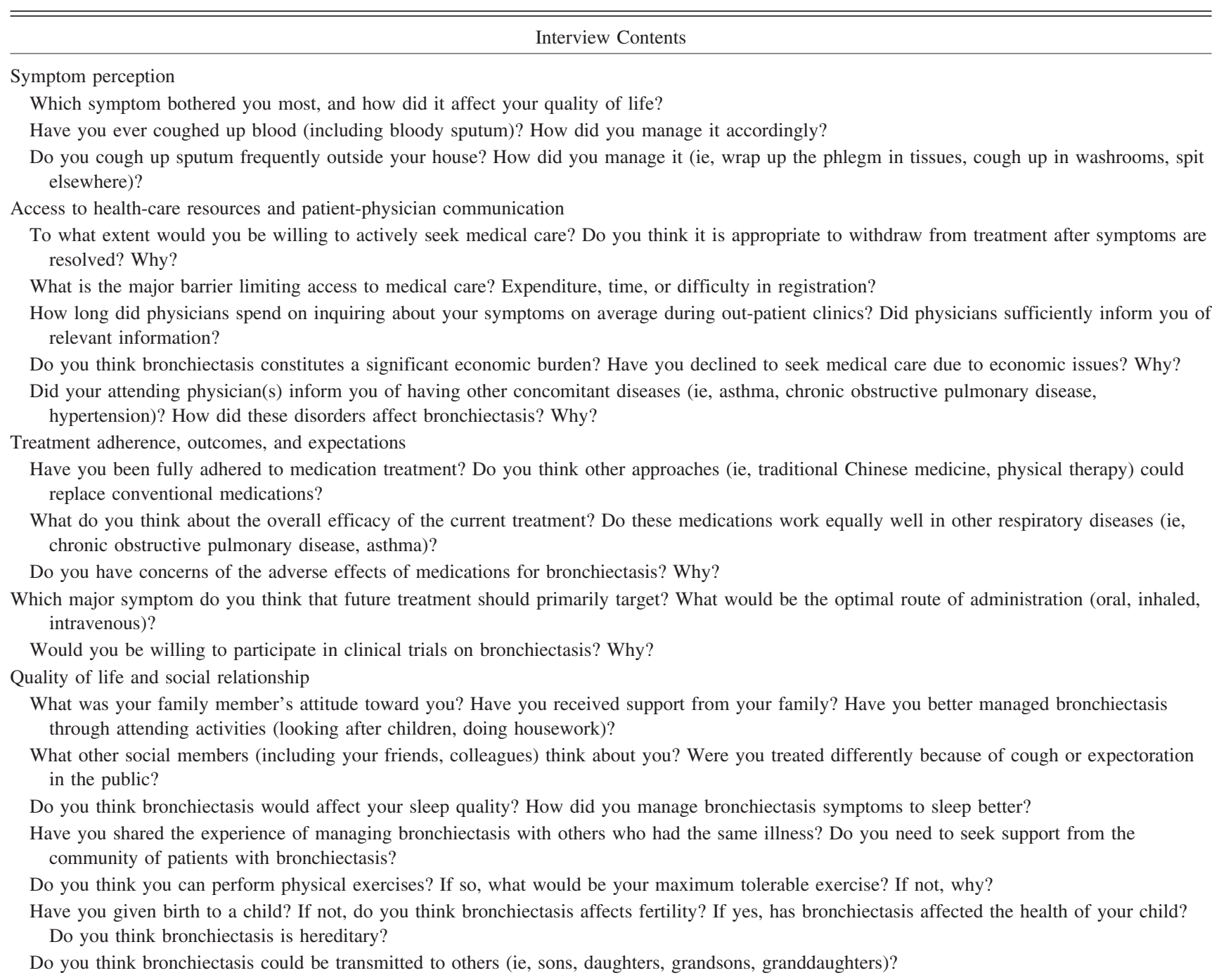

\section{Access to Health-Care Resources and Subject-Physician Communication}

Early management might improve long-term outcomes; however, the subjects were ambivalent to seeking health care. Most subjects immediately sought health care when they experienced discomfort, whereas some came for regular medication refills.

- "I would see the doctor when coughing up blood or having a lot of phlegm . . . and will take [medications] if doctors prescribed them" (subject no. 32: female, age $20 \mathrm{y})$.

But some preferred delayed hospital visits.

- "I seldom [go to the hospital] . . . because if I have fever ... I've got medicine at home ... but I would [go to the hospital] when I felt it became severe enough" (subject no. 28: male, age $53 \mathrm{y}$ ).

Importantly, only half frequently withdrew medications once symptoms were alleviated.

- "Sometimes I would skip taking some [medications] when I am feeling slightly better" (subject no. 44: female, age $46 \mathrm{y}$ ).

Most subjects commented that self-management was effective.

- "I would do some farming, take a walk, or play some cards ... to distract myself [from bronchiectasis]." (subject no. 46: male, age $67 \mathrm{y}$ ).

Perception of disease burden varied, but most subjects rated their monthly expenditure as low or moderate. To 
Table 2. Clinical Characteristics of Participants Finally Included in the Interview

\begin{tabular}{|c|c|}
\hline Parameter & Results \\
\hline \multicolumn{2}{|l|}{ Anthropometry } \\
\hline Age, mean \pm SD y & $49.1 \pm 13.6$ \\
\hline Height, mean $\pm \mathrm{SD} \mathrm{cm}$ & $161.9 \pm 8.2$ \\
\hline Body mass index, mean $\pm \mathrm{SD} \mathrm{kg} / \mathrm{m}^{2}$ & $20.7 \pm 3.4$ \\
\hline Females, $n(\%)$ & $34(56.7)$ \\
\hline Never-smokers, $n(\%)$ & $55(91.7)$ \\
\hline \multicolumn{2}{|l|}{ Disease characteristics } \\
\hline Duration of bronchiectasis symptoms, y & $16.0(18.2)$ \\
\hline $\begin{array}{l}\text { Exacerbation frequency within } 1 \text { year, } \\
\text { times/person }\end{array}$ & $1.0(2.0)$ \\
\hline No. of bronchiectatic lobes, $n$ & $4.0(2.0)$ \\
\hline HRCT total score, mean $\pm \mathrm{SD}$ & $8.5 \pm 4.0$ \\
\hline $\begin{array}{l}\text { Bronchiectasis Severity Index score, } \\
\text { mean } \pm \text { SD }\end{array}$ & $5.9 \pm 3.5$ \\
\hline \multicolumn{2}{|l|}{ Bronchiectasis etiology, $n(\%)$} \\
\hline Idiopathic & $25(41.7)$ \\
\hline Post-infectious & $21(35.0)$ \\
\hline Other known etiologies & $14(23.3)$ \\
\hline \multicolumn{2}{|l|}{ Sputum bacteriology, $n(\%)$} \\
\hline Pseudomonas aeruginosa & $21(35.0)$ \\
\hline Other pathogenic bacteria* & $14(23.3)$ \\
\hline Commensals $\dagger$ & $25(41.7)$ \\
\hline \multicolumn{2}{|l|}{ Comorbid diseases, $n(\%)$} \\
\hline Rhinosinusitis & $24(40.0)$ \\
\hline Others $\ddagger$ & $3(5.0)$ \\
\hline \multicolumn{2}{|l|}{$\begin{array}{l}\text { Subjects who used medications within } 6 \text { mo, } \\
n(\%)\end{array}$} \\
\hline Mucolytics & $45(75.0)$ \\
\hline Macrolides & $25(41.7)$ \\
\hline Inhaled corticosteroids & $20(33.3)$ \\
\hline \multicolumn{2}{|c|}{$\begin{array}{l}=60 \text {. Continuous variables are presented as mean } \pm \text { standard deviation for data with } \\
\text { normal distribution, or median (interquartile range) for data with non-normal distribution, } \\
\text { respectively. The data with the parenthesis for "Disease characteristics" denoted those with } \\
\text { non-normal distribution. } \\
\text { None of the subjects was using inhaled or oral antibiotics at the time of the study. } \\
\text { * Haemophilus influenzae, Haemophilus parainfluenzae, Klebsiella species, Escherichia coli, } \\
\text { Proteus mirabilis; other known etiologies included immunodeficiency }(n=7) \text {, } \\
\text { gastroesophageal reflux disease }(n=2) \text {, asthma }(n=1 \text {, clinically stable), cystic fibrosis } \\
\text { transmembrane regulator-associated disorder }(n=1) \text {, diffuse panbronchiolitis }(n=1) \text {, } \\
\text { Kartagener syndrome }(n=1) \text {, lung mal-development }(n=1) \text {. } \\
\dagger \text { Neisseria, } \alpha \text {-Streptococcus hemolyticus, Bacilli diphtheria, and coagulase-negative } \\
\text { Staphylococcus. } \\
\ddagger \text { Included hypertension }(n=1[1.7 \%]) \text {, hepatitis }(n=1[1.7 \%]) \text {, and primary aldosteronism } \\
(n=1[1.7 \%]) \text {. A minor proportion of subjects was deemed as having dual etiologies; } \\
\text { therefore, the total percentage of individual etiology slightly exceeded } 100 \% \text {. } \\
\text { HRCT = high-resolution computed tomography }\end{array}$} \\
\hline
\end{tabular}

most subjects, the economic burden did not constitute a major barrier for seeking health care.

In China, the subjects sometimes seek health care in tertiary hospitals without referral. Despite this, most subjects commented that attending long-term follow-up visits was challenging. Reasons included "costly," followed by "a long wait time," and the "difficulty in registration." In clinics, the median duration of consultation was $10 \mathrm{~min}$ per subject. Most subjects were satisfied with physician's provision of information for bronchiectasis management in tertiary hospitals, whereas others felt dissatisfied.

- "It seemed that, apart from symptom inquiry and prescription of medicine ... they [doctors] had said nothing else" (subject no. 8: female, age 45 y).

\section{Medication Adherence, Outcomes, and Expectations}

Subjects' attitudes toward treatment were diverse. First, most subjects were adherent to maintenance therapy (selfreported use of macrolides, mucolytics, chest physiotherapy, inhaled bronchodilators), whereas the remaining subjects administered therapy intermittently (during exacerbations and/or colds, or when having hemoptysis). Second, Western medications were mostly used for maintenance or intermittent treatment. We asked the subjects whether traditional Chinese medicine could substitute for Western medications, and a few gave completely positive comments. Importantly, approximately one fifth of the subjects commented that both types of medications were complementary and might add to current treatment. Most subjects gave ambiguous responses because they had never been prescribed traditional Chinese medicines.

- "We can combine [the effects of traditional Chinese medicine and Western medicine]. . . That is, traditional Chinese medicine mainly may help supplement the treatment" (subject no. 27: female, age $66 \mathrm{y}$ ).

- Treatment outcomes are dependent on medication adherence. ${ }^{18}$ We asked the subjects to provide global selfassessments or ratings of their previous therapeutic outcomes. More than half were rated as satisfactory, followed by moderate and poor. Positive responses included "Overall satisfactory, but I don't know whether it [bronchiectasis] may get healed" (subject no. 52: female, age $68 \mathrm{y}$ ), whereas negative responses included "Based on my previous experience [on the effects], the overall outcomes were not good. . . . It seemed that there is no difference whether I take the medications or not [on managing coughing up blood]" (subject no. 20: male, age 75 y). For most subjects, therapeutic outcomes of bronchiectasis resembled those of COPD.

Half of the subjects showed concern about adverse effects of treatment, mostly related to gastrointestinal problems and frailty.

- "When taking medications, I felt my hands trembling and felt fatigued, which were ameliorated after withdrawal [of medications]" (subject no. 45, male, age $37 \mathrm{y})$.

Despite this, most subjects expected that novel medications would resolve excessive coughing and sputum 
Table 3. Symptom Perception

\begin{tabular}{|c|c|c|}
\hline Interview Question & Response & Subject Comments \\
\hline \multirow[t]{4}{*}{ Predominant symptom and impact } & Agreed & "I kept coughing everyday" (subject no. 51: female, age 43 y) \\
\hline & & $\begin{array}{l}\text { "Only when it [the sputum] was coughed up that I would feel comfortable. . . I would } \\
\text { immediately cough it out when I've got the phlegm" (subject no. 23: female, age } \\
50 \mathrm{y} \text { ) }\end{array}$ \\
\hline & & $\begin{array}{l}\text { "I sometimes felt short of breath when doing housework or during exertion" (subject } \\
\text { no. 14: male, age } 35 \mathrm{y} \text { ) }\end{array}$ \\
\hline & Disagreed & $\begin{array}{l}\text { "My symptoms are not prominent and my daily life has not been affected." (subject no. } \\
60 \text { : male, age } 43 \text { y) }\end{array}$ \\
\hline \multirow[t]{2}{*}{ Management of hemoptysis } & Active & $\begin{array}{l}\text { "Coughing up blood was sometimes troublesome. . . I would always immediately go } \\
\text { to the hospital prescribing medication once I coughed up blood." (subject no. 43: } \\
\text { male, age } 35 \mathrm{y} \text { ) }\end{array}$ \\
\hline & Disregarded & $\begin{array}{l}\text { "I am simply not bothered and took no action [when coughing up blood"] (subject no. } \\
\text { 31: male, age } 50 \text { y) }\end{array}$ \\
\hline \multirow[t]{2}{*}{ Management of sputum production } & Formal & $\begin{array}{l}\text { "I would cough up [phlegm] in the toilet in the morning or in the trash can at night." } \\
\text { (subject no. 09: female, age } 43 \mathrm{y} \text { ) }\end{array}$ \\
\hline & Casual & $\begin{array}{l}\text { "Sometimes I had to spit beside trees [on the sidewalk] when I'm [walking] on the } \\
\text { street." (subject no. 46: male, age } 67 \text { y) }\end{array}$ \\
\hline
\end{tabular}

Table 4. Access to Health-Care Resources and Subject-Physician Communication

\begin{tabular}{|c|c|c|}
\hline Interview Question & Response & Subject Comments \\
\hline \multirow[t]{2}{*}{ Willingness to seek health care } & Active & $\begin{array}{l}\text { "I would see the doctor when coughing up blood or having a lot of phlegm . . . and will take } \\
\text { [medications] if doctors prescribed them." (subject no. 32: female, age } 20 \text { y) }\end{array}$ \\
\hline & Passive & $\begin{array}{l}\text { "I seldom[go to the hospital] ... because if I have fever... I've got medicine at home ... } \\
\text { but would [go to the hospital] when I felt it became severe enough" (subject no. 28: male, } \\
\text { age } 53 \mathrm{y} \text { ) }\end{array}$ \\
\hline \multirow[t]{2}{*}{$\begin{array}{l}\text { Major barrier limiting access } \\
\text { to health care }\end{array}$} & Duration & $\begin{array}{l}\text { "The main issue is time } \ldots \text { and I live somewhat far away [from the hospital]." (subject no. } \\
\text { 39: female, age } 48 \text { y) }\end{array}$ \\
\hline & Registry & $\begin{array}{l}\text { "Sometimes it's difficult to even get registered [for consultation]" (subject no. 26: male, age } \\
37 \mathrm{y})\end{array}$ \\
\hline \multirow{3}{*}{$\begin{array}{l}\text { Duration of physician } \\
\text { consultation }\end{array}$} & Short & "6-7 min" (subject no. 34: female, age 57 y) \\
\hline & Moderate & "some 10 min" (subject no. 36: male, age 42 y) \\
\hline & & $\begin{array}{l}\text { "The time to describe my symptoms and for the doctors to offer consultation ... [hesitated a } \\
\text { while] usually takes about } 10 \text { min" (subject no. 14: male, age } 35 \mathrm{y} \text { ) }\end{array}$ \\
\hline \multirow[t]{2}{*}{$\begin{array}{l}\text { Physician's provision of } \\
\text { knowledge }\end{array}$} & Sufficient & $\begin{array}{l}\text { "Doctors here [in tertiary hospital] have informed me with sufficient information on my } \\
\text { conditions." (subject no. 18: male, age } 50 \mathrm{y} \text { ) }\end{array}$ \\
\hline & Insufficient & $\begin{array}{l}\text { "It seemed that, apart from symptom inquiry and prescription of medication, and then . } \\
\text { they [doctors] had said nothing else" (subject no. 8: female, age } 45 \mathrm{y} \text { ) }\end{array}$ \\
\hline \multirow[t]{3}{*}{$\begin{array}{l}\text { Concomitant disease and } \\
\text { impact }\end{array}$} & Upper airway & $\begin{array}{l}\text { "I've got rhinosinusitis ... it has moderate negative effects because it might worsen my } \\
\text { bronchiectasis [is linked through the respiratory tract]." (subject no. } 41 \text { : male, age } 24 \mathrm{y} \text { ) }\end{array}$ \\
\hline & Lower airway & $\begin{array}{l}\text { "I have chronic obstructive pulmonary disease. . . It quite affects my bronchiectasis. } \\
\text { Although I keep taking the medicines, it [chronic obstructive pulmonary disease] has made } \\
\text { my bronchiectasis more severe" (subject no. 11: female, age } 69 \mathrm{y} \text { ) }\end{array}$ \\
\hline & Systemic & $\begin{array}{l}\text { "I have hypertension. ... I felt that it was not associated with my bronchiectasis." (subject } \\
\text { no. 33: female, age } 65 \text { y) }\end{array}$ \\
\hline
\end{tabular}

production. Both oral and inhalation are preferred routes. Privacy is probably the main reason that drove some subjects' preference to inhalation therapy.

- "I prefer oral medications because they are the most convenient . . . inhalation should be done privately and devices are needed for intravenous injection" (subject no. 21: male, age $39 \mathrm{y}$ ).
Finally, most subjects were willing to participate in clinical trials, whereas a minority of the subjects explicitly rejected participating.

- "With pleasure, I would participate, because I think that since I've got it [bronchiectasis], and current medical science and medications are not effective, the investigators would strive to make ongoing improvement. So 


\section{Health Perception and Behavior in Bronchiectasis}

Table 5. Treatment Adherence, Outcomes, and Expectations

\begin{tabular}{|c|c|c|}
\hline Interview Question & Response & Subject Comments \\
\hline \multirow[t]{2}{*}{ Adherence } & Positive & "I have been taking whatever [medications] the doctors prescribed" (subject no. 48 : female, age $22 \mathrm{y}$ ) \\
\hline & Negative & $\begin{array}{l}\text { "Sometimes I would skip taking some [medications] when I am feeling slightly better" (subject no. } \\
\text { 44: female, age } 46 \mathrm{y} \text { ) }\end{array}$ \\
\hline \multirow[t]{3}{*}{$\begin{array}{l}\text { The role of TCM and other } \\
\text { therapies }\end{array}$} & Positive & $\begin{array}{l}\text { "In some sense, I do recognize the role of TCM on [treating] my disease [bronchiectasis]" (subject } \\
\text { no. 20: male, age } 75 \text { y) }\end{array}$ \\
\hline & Complementary & $\begin{array}{l}\text { "We can combine [the effects of TCM and Western medicine].... That is, TCM mainly may help } \\
\text { supplement the treatment" (subject no. 27: female, age } 66 \mathrm{y} \text { ) }\end{array}$ \\
\hline & Negative & "TCM cannot replace Western medicine." (subject no. 35: male, age 38 y) \\
\hline \multirow[t]{3}{*}{ Treatment outcomes } & Positive & $\begin{array}{l}\text { "Overall satisfactory, but I don’t know whether it [bronchiectasis] can be cured" (subject no. 52: } \\
\text { female, age } 68 \text { y) }\end{array}$ \\
\hline & Neutral & "Frankly speaking, I think the overall outcome is modest" (subject no. 35: male, age 38 y) \\
\hline & Negative & $\begin{array}{l}\text { "Based on my previous experience [on the effects], the overall outcomes were not good. . . It } \\
\text { seemed that there is no difference whether I take the medications or not [on managing coughing up } \\
\text { blood]" (subject no. 20: male, age } 75 \text { y) }\end{array}$ \\
\hline \multirow[t]{4}{*}{ Concerns of adverse effects } & Positive & $\begin{array}{l}\text { "When taking medications, I felt my hands trembling and felt fatigued, which were ameliorated after } \\
\text { withdrawal [of medications]." (subject no. } 45 \text { : male, age } 37 \mathrm{y} \text { ) }\end{array}$ \\
\hline & & $\begin{array}{l}\text { "I felt that I would be addicted and rely too much on medications upon prolonged use." (subject no. } \\
49 \text { : male, age } 59 \text { y) }\end{array}$ \\
\hline & Neutral & $\begin{array}{l}\text { "For now I have not felt any [of the adverse effects] except for the . . antibiotics. . . [Because] I } \\
\text { would have poor sleep upon taking it [antibiotics]." (subject no. 30: female, age } 54 \text { y) }\end{array}$ \\
\hline & Negative & "There are no adverse effects at the moment." (subject no. 13: male, age 45 y) \\
\hline \multirow[t]{3}{*}{ Target for future medicine } & Inhaled & $\begin{array}{l}\text { "Inhaled [medicine] is better in helping me expel, it [the sputum] would come out easier" (subject no. } \\
\text { 37: female, age } 63 \mathrm{y} \text { ) }\end{array}$ \\
\hline & Oral & $\begin{array}{l}\text { "I prefer oral medications because they are the most convenient ... inhalation should be done } \\
\text { privately; devices are needed for intravenous injection." (subject no. } 21 \text { : male, age } 39 \text { y) }\end{array}$ \\
\hline & Intravenous & $\begin{array}{l}\text { "[I prefer] intravenous [injection] . . . It [bronchiectasis] got better more rapidly, say generally } 1 \text { to } 2 \\
\text { days, but it would take } 5 \text { or } 7 \text { days when treated with oral [medications]." (subject no. 29: male, } \\
\text { age } 25 \text { y) }\end{array}$ \\
\hline \multirow[t]{3}{*}{$\begin{array}{l}\text { Willingness to participate } \\
\text { in clinical trials }\end{array}$} & Positive & $\begin{array}{l}\text { "With pleasure, I would participate, because I think that since I've got it [bronchiectasis], and current } \\
\text { medical science and medications are not effective, the investigators would strive to make ongoing } \\
\text { improvement. So why shouldn't we take a chance?" (subject no. 21: male, age } 39 \text { y) }\end{array}$ \\
\hline & Neutral & $\begin{array}{l}\text { "[The clinical trial] should not be too burdensome [to me }] \text {... I would need that the novel } \\
\text { medication that can improve my symptoms to be an oral medication." (subject no. 13: male, age } \\
45 \mathrm{y} \text { ) }\end{array}$ \\
\hline & Negative & $\begin{array}{l}\text { "My son asked me not to participate [in clinical trials] . . I myself am not inclined to take part as } \\
\text { well, especially, if based on the current status, which is not severe enough." (subject no. 03: } \\
\text { female, age } 59 \mathrm{y} \text { ) }\end{array}$ \\
\hline
\end{tabular}

why shouldn't we ... have a try?" (subject no. 21: male, age $39 \mathrm{y}$ ).

- Some subjects took the wait-and-see attitude.

- "[The clinical trial] should not be too burdensome [to me]. . . . I would need the novel medication that can improve my symptoms to be an oral medication" (subject no. 13: male, age $45 \mathrm{y}$ ).

\section{Quality of Life and Social Relationships}

Family support was crucial to the subjects. Among most subjects, family members offered more support since their clinical diagnosis. Symptoms might elicit embarrassment: most subjects felt that they were treated as healthy, but some friends or relatives might not have been aware that they had bronchiectasis. However, some subjects did face public stigma.

Subjects held different views regarding participation in support groups where ideas and/or experience could be shared. Although no such organization exists in China, most were willing to participate, whereas some directly declined.

- "I look forward to having such communities to help alleviate the psychological impact and pressure bronchiectasis has had on me" (subject no. 41: male, age 24 y).

- "I myself was skeptical on whether the doctors are prescribing the right medication to [help] my symptoms, let alone other patients." (subject no. 20: male, age $75 \mathrm{y})$. 
Table 6. Quality of Life and Social Relationship

\begin{tabular}{|c|c|c|}
\hline Interview Question & Response & Subject Comments \\
\hline \multirow[t]{2}{*}{ Family support } & Supportive & $\begin{array}{l}\text { "They [the family members] would try to persuade me to stop smoking and ask me to do more } \\
\text { exercises." (subject no. 15: male, age } 58 \text { y) }\end{array}$ \\
\hline & Neutral & $\begin{array}{l}\text { "My parents would not pay particular attention [to my disease] because it is not severe enough. . . } \\
\text { None of my friends even knew I've got the disease [bronchiectasis]." (subject no. 45: male, age } 37 \text { y) }\end{array}$ \\
\hline \multirow[t]{3}{*}{ Self-management } & Useful & $\begin{array}{l}\text { "I would do some farming, take a walk, or play some cards . . . to distract myself [from } \\
\text { bronchiectasis]." (subject no. 46: male, age } 67 \mathrm{y})\end{array}$ \\
\hline & Neutral & "I can still manage my normal daily life." (subject no. 41: male, age 24 y) \\
\hline & Useless & $\begin{array}{l}\text { "I felt restless, and found myself being somewhat anxious. It takes a long time to perform task ... } \\
\text { sometimes I would be worried and come to see the doctor. . . But I do forget to take my } \\
\text { medications quite often." (subject no. 52: female, age } 68 \mathrm{y} \text { ) }\end{array}$ \\
\hline \multirow[t]{3}{*}{ Social support } & Supportive & "They are supportive and would not treat me differently" (subject no. 01: female, age $37 \mathrm{y}$ ) \\
\hline & Neutral & "They would still play cards with me everyday" (subject no. 33: female, age 65 y) \\
\hline & Unsupported & $\begin{array}{l}\text { "I have never dared to tell anyone [about bronchiectasis]. . . None of my colleagues knew that I've got } \\
\text { bronchiectasis ... but they would often ask how am I doing and why do I kept coughing..... I } \\
\text { simply responded to them that I've caught a cold. . . . I do feel they did treat me differently." } \\
\text { (subject no. } 41 \text { : male, age } 24 \text { y) }\end{array}$ \\
\hline \multirow[t]{4}{*}{ Impact on sleep quality } & $\begin{array}{l}\text { Poor but } \\
\text { manageable }\end{array}$ & $\begin{array}{l}\text { "Sometimes I would cough all the way till I wake up in morning . . . if I had light diet in the day I } \\
\text { would seldom cough at night. . . . I would get up to boil up some soup to drink" (subject no. 23: } \\
\text { female, age } 50 \text { y) }\end{array}$ \\
\hline & $\begin{array}{l}\text { Poor but not } \\
\text { manageable }\end{array}$ & $\begin{array}{l}\text { "I got lots of phlegm the moment I lie on bed at night. . . I often sleep poorly while napping at } \\
\text { noontime. When I felt discomfort from the phlegm I will cough it up" (subject no. 43: male, age } \\
35 \text { y) }\end{array}$ \\
\hline & & $\begin{array}{l}\text { "Yes, it [bronchiectasis] affected my sleep. ... I became fatigued because I cannot have a good sleep at } \\
\text { night. . . I would intentionally had dinner and did [postural] drainage earlier each night, and thought } \\
\text { that this would make me sleep better, but it still failed, and I would still get up all night to expel the } \\
\text { phlegm" (subject no. 11: female, age } 69 \mathrm{y} \text { ) }\end{array}$ \\
\hline & Minimal & $\begin{array}{l}\text { "I can have a good sleep at night. It [bronchiectasis] did not affect my sleep except during } \\
\text { exacerbations." (subject no. 29: male, age } 25 \mathrm{y} \text { ) }\end{array}$ \\
\hline \multirow[t]{3}{*}{$\begin{array}{l}\text { Joining clubs and sharing } \\
\text { information }\end{array}$} & Positive & $\begin{array}{l}\text { "I look forward to having such communities to help alleviate the psychological impact and pressure } \\
\text { bronchiectasis had on me" (subject no. } 41 \text { : male, age } 24 \mathrm{y} \text { ) }\end{array}$ \\
\hline & Neutral & $\begin{array}{l}\text { "Well, it is human nature, you know ... we do have a sense of the so-called self-protection. ... In my } \\
\text { opinion, the Chinese people do not wish others to know much about such things [private matters]" } \\
\text { (subject no. 35: male, age } 38 \text { y) }\end{array}$ \\
\hline & Negative & $\begin{array}{l}\text { "I myself was skeptical on whether the doctors are prescribing the right medication to [help] my } \\
\text { symptoms, let alone other subjects." (subject no. } 20 \text { : male, age } 75 \text { y) }\end{array}$ \\
\hline \multirow[t]{6}{*}{ Physical exercise } & Walking & "I can walk up to 3 hours after dinner." (subject no. 16: female, age 47 y) \\
\hline & Jogging & "I do not have much time to exercise, but I can jog for a little while." (subject no. 34: female, age 57 y) \\
\hline & Other means & $\begin{array}{l}\text { "I could play badminton about thrice weekly and would also do some hiking." (subject no. 05: male, } \\
\text { age } 26 \text { y) }\end{array}$ \\
\hline & & $\begin{array}{l}\text { "Sometimes, I would do square dancing when I am back in my hometown . . . but I cannot do jogging." } \\
\text { (subject no. 33: female, } 65 \text { y) }\end{array}$ \\
\hline & & "Since I moved to the 9th floor I have only gone for Tai Chi twice." (subject no. 52: female, age 68 y) \\
\hline & $\begin{array}{r}\text { Almost no } \\
\text { exercise }\end{array}$ & $\begin{array}{l}\text { "I seldom [did exercise }] \ldots \text { mostly just some walking and jogging. . . . At most [I could] jog for } 15 \\
\text { min . . because it felt tiring to do all these" (subject no. 44: female, age } 46 \mathrm{y} \text { ) }\end{array}$ \\
\hline \multirow[t]{3}{*}{ Fertility } & Minor impact & $\begin{array}{l}\text { "I have been afraid of this [infertility], I do have a slight fear that my children would inherit the } \\
\text { disease"(subject no. 32: female, age } 20 \text { y) }\end{array}$ \\
\hline & Unknown & "I am divorced . . . had rarely thought of this [issue]" (subject no. 14: male, age 45 y) \\
\hline & Adverse impact & $\begin{array}{l}\text { "I think that it [bronchiectasis] affects fertility. . . Coughing led to a miscarriage during my previous } \\
\text { pregnancy." (subject no. 54: female, age } 39 \text { y) }\end{array}$ \\
\hline \multirow[t]{3}{*}{ Infectiousness } & No impact & $\begin{array}{l}\text { "For now [I believe that] it [bronchiectasis] would be transmitted to my children, but [I'm] not sure if } \\
\text { bronchiectasis is hereditary' (subject no. 19: male, age } 59 \mathrm{y} \text { ) }\end{array}$ \\
\hline & Unknown & $\begin{array}{l}\text { "I do fear that it [bronchiectasis] can be transmitted to others although it is said not to be ... what if it } \\
\text { really can be transmitted then it will be bad" (subject no. 03: female, age } 59 \text { y) }\end{array}$ \\
\hline & Adverse impact & "I do worry that it [bronchiectasis] may be infectious." (subject no. 56: male, age 74 y) \\
\hline
\end{tabular}

$\mathrm{TCM}=$ traditional Chinese medicine

Most subjects stated that bronchiectasis negatively affected sleep quality, particularly during exacerbations.

- "I got lots of phlegm the moment I lay in bed at night. ... I often sleep poorly while napping at noontime. When I felt discomfort from the phlegm I will cough it up" (subject no. 43: male, age $35 \mathrm{y}$ ).

Major methods for dealing with disturbed sleeping included drinking some water and coughing up phlegm.
Most subjects could exercise to different extents. But some attempted to avoid exercise.

- "I seldom [exercise] . . . mostly just some walking and jogging. . . . At most [I could] jog for $15 \mathrm{~min}$. . . because it felt tiring to do all these" (subject no. 44: female, age 46 y).

Of all exercises, walking was preferred, yet others preferred Tai Chi, playing badminton, or square dancing (which is popular in China). 
- "I can walk up to 3 hours after dinner" (subject no. 16: female, age 47 y).

Since implementation of the 2-child policy in China, more families planned to have another child. We inquired about subjects' views of fertility associated with bronchiectasis. Most had a child and showed no concern of negative impacts on fertility, although some did.

- "I think that it [bronchiectasis] affects fertility.... Coughing led to a miscarriage during my previous pregnancy" (subject no. 54: female, age 39 y).

- Most subjects believed that bronchiectasis would not affect their children, but suspicion was raised "when my mother was diagnosed as having bronchiectasis" (subject no. 07: female, age $45 \mathrm{y}$ ).

Most subjects believed that bronchiectasis was not hereditary.

- "For now [I believe that] it [bronchiectasis] would not be transmitted to my children, but [I'm] not sure if bronchiectasis is hereditary" (subject no.19: male, age 59 y).

Finally, most subjects commented that they had no worries about potential infectiousness.

- "We value hygiene pretty much. .. . Though we share dishware together, we have a disinfection cabinet, and sometimes [we also disinfect] using boiling water" (subject no. 33: female, age 65 y).

\section{Discussion}

This study extended findings on self-management of bronchiectasis. ${ }^{17}$ The diverse symptom perceptions that we encountered echoed the recent findings of highly individualized bronchiectasis symptoms. ${ }^{18}$ In some patients, hemoptysis carries substantial psychological burden and could be the leading drive for seeking health care. ${ }^{21}$

The subjects with bronchiectasis had conflicting opinions on whether and when they should seek health care. There was a discrepancy between symptom perception and behaviors. The underlying causes may be multifaceted, including the health-care system, cost associated with bronchiectasis management, the need to balance symptom burden, perceived barriers to seek health care, and the intrinsic motivation to opt for better therapeutic outcomes. Although most subjects perceived themselves as living normally, they sought to protect themselves by suppressing the manifestation of symptoms (eg, frequent or massive sputum expectoration) or by concealing their diagnosis from others. Self-efficacy may help explain that these subjects tended to feel competent when performing different tasks. ${ }^{22}$
Overall medication adherence was suboptimal, and concerns regarding adverse effects still exist. We found that subjects' medication adherence was associated with their own beliefs, trust in health-care professionals, treatment response, and acceptance of the disease and treatment. ${ }^{18}$ Therefore, the barriers and limited motivation to seek health care in some subjects may help inform the suboptimal medication adherence. Of potential barriers to self-manage bronchiectasis, information deficits could be addressed by providing health-care information and by improving physician-patient communication. ${ }^{20}$ As addressed in our previous work, ${ }^{23}$ medication adherence correlated significantly with long-term outcomes.

Intriguingly, symptom perception may be collectively shaped by socioeconomic status, treatment outcomes, and previous interactions with physicians. For instance, because of "the difficulty in registration," "the costs," inadequate disposition by attending physicians," and "potential side effects of medications," many subjects were reluctant to seek health care until significant symptom aggravation, which rendered routine follow-up challenging. Nonetheless, because most subjects recognized the limitations of currently available treatment, they remained open to clinical trials with novel medications or supplementation with traditional Chinese medicine although it was never prescribed. Both oral and inhaled medications seemed to be well accepted by most of the subjects, which reflected the subjects' expectancy and value of treatment strategies.

In real-world practice, many subjects in China directly sought health care from tertiary hospitals, with unrealistic expectations of a complete cure for their bronchiectasis. The stark contrast with actual outcomes might have led to frustration after exhaustive consultations with physicians, and the growing dissatisfaction and/or mistrust with medicine could result in non-adherence. This may be compounded by the insufficient time for consultation at clinics, where physicians are frequently overwhelmed by their daily work load. Although many developed countries have medical systems that differ from those in China, our findings might apply in many other developing countries where healthcare resources are largely insufficient. A practical implication is that addressing unmet medical needs could be achieved via improving physician-patient communication and patient health education. Understanding the factors that impair quality of life may complement medication treatment via cognitive therapy that could help patients establish appropriate perceptions of their health, alleviate social embarrassment, and ameliorate anxiety and depression.

Despite mostly sufficient family support, the subjects still had impaired quality of life and sought to distract themselves from bronchiectasis. Most subjects were not concerned that bronchiectasis could reduce their fertility or that bronchiectasis might be hereditary. However, some subjects had major anxiety and depression. Therefore, physicians should remain vigilant to psychological interventions 
at clinics. These clinical questions, along with European Multicentre Bronchiectasis Audit and Research Collaboration (EMBARC) Clinical Research Collaboration document, ${ }^{24}$ were previously highlighted as research priorities. ${ }^{25}$

This study was limited by the generalizability to other health-care settings worldwide ${ }^{17,26}$ because of the singlecenter study setting. Provision of an informational letter to willing participants would better identify additional ethical considerations. Translation of Chinese into English might inevitably result in information loss. Despite these limitations, many findings were universal issues regarding global bronchiectasis management, as evidenced by the commonality reported in recent literature from Europe. ${ }^{17-19}$ Diverse health perceptions and behaviors, and factors that influence quality of life in bronchiectasis echo the findings of recent studies from developed countries. ${ }^{17-19}$ Our study addressed many neglected but critically important issues in real-world practice, particularly in Asian countries where bronchiectasis investigation remains largely insufficient.

Therefore, some findings related to the local culture might better reflect real-world practice in many developing countries where bronchiectasis management has not been sufficiently documented. The present study provided further support for the likelihood that patients respond across the spectrum of behaviors and beliefs. For clinical management of bronchiectasis worldwide, building on coping mechanisms that work for each individual might lead to improved disease self-management or quality of life. Finally, this study confirmed that responses of Chinese adults with bronchiectasis echoed subjects from other cultures; therefore, interventions found useful in other countries (when tailored to the Chinese health-care system and cultural norms) might help to guide clinical trials in China.

\section{Conclusions}

The subjects with bronchiectasis developed various symptom perceptions from highly distressed to barely disturbed and had conflicting opinions on whether and when they should seek health-care services (from active consultations to being totally passive or resistant). These findings could help health-care staff and policymakers become aware of disease burden and better meet the needs of patients with bronchiectasis worldwide.

\section{ACKNOWLEDGMENTS}

We thank Dr Kai Sen Tan (Department of Otolaryngology, Yong Loo Lin School of Medicine, National University of Singapore) and Dr Mei Jiang (State Key Laboratory of Respiratory Disease, National Clinical Research center for Respiratory Disease, Guangzhou Institute of Respiratory Health, First Affiliated Hospital of Guangzhou Medical University, Guangzhou Medical University) for their constructive comments about the manuscript. We wholeheartedly thank all subjects for their participation in this study.

\section{REFERENCES}

1. Chalmers JD, Aliberti S, Polverino E, Vendrell M, Crichton M, Loebinger M, et al. on behalf of EMBARC. The EMBARC European Bronchiectasis Registry: protocol for an international observational study. ERJ Open Res 2016;2(1): pii: 00081-2015.

2. Lin JL, Xu JF, Qu JM. Bronchiectasis in China. Ann Am Thorac Soc 2016;13(5):609-616.

3. European Commission. Policy: rare diseases - what are they? https:// ec.europa.eu/health/rare_diseases/overview_en. Accessed May 28, 2018.

4. Weycker D, Edelsberg J, Oster G, Gregory T. Prevalence and economic burden of bronchiectasis. Clin Pulm Med 2005;12(4):205209.

5. Quint JK, Millett ER, Joshi M, Navaratnam V, Thomas SL, Hurst JR, et al. Changes in the incidence, prevalence and mortality of bronchiectasis in the UK from 2004 to 2013: a population-based cohort study. Eur Respir J 2016;47(1):186-193.

6. Kwak HJ, Moon JY, Choi YW, Kim TH, Sohn JW, Yoon HJ, et al. High prevalence of bronchiectasis in adults: analysis of CT findings in a health screening program. Tohoku J Exp Med 2010;222(4):237242.

7. Chalmers JD, Aliberti S, Blasi F. Management of bronchiectasis in adults. Eur Respir J 2015;45(5):1446-1462.

8. Ellis HC, Cowman S, Fernandes M, Wilson R, Loebinger MR. Predicting mortality in bronchiectasis using BSI and FACED scores: a 19-year cohort study. Eur Respir J 2016;47(2):482-489.

9. Pasteur MC, Bilton D, Hill AT, on behalf of the British Thoracic Society Bronchiectasis (non-CF) Guideline Group. British Thoracic Society guidelines for non-CF bronchiectasis. Thorax 2010;65(Suppl 1): i1-i58.

10. Gao Y, Guan W, Xu G, Lin Z, Tang Y, Lin Z, et al. Sleep disturbances and health-related quality of life in adults with steady-state bronchiectasis. PLoS One 2014;9(7):e102970.

11. Gao YH, Guan WJ, Zhu YN, Chen RC, Zhang GJ. Anxiety and depression in adult outpatients with bronchiectasis: Associations with disease severity and health-related quality of life. Clin Respir J 2018; 12(4):1485-1494.

12. Chalmers JD, Goeminne P, Aliberti S, McDonnell MJ, Lonni S, Davidson J, et al. The bronchiectasis severity index: An international derivation and validation study. Am J Respir Crit Care Med 2014; 189(5):576-585.

13. Haworth CS, Foweraker JE, Wilkinson P, Kenyon RF, Bilton D. Inhaled colistin in patients with bronchiectasis and chronic Pseudomonas aeruginosa infection. Am J Respir Crit Care Med 2014; 189(8):975-982.

14. Wong C, Jayaram L, Karalus N, Eaton T, Tong C, Hockey H, et al. Azithromycin for prevention of exacerbations in non-cystic fibrosis bronchiectasis (EMBRACE): a randomised, double-blind, placebocontrolled trial. Lancet 2012;380(9842):660-667.

15. Wilson R, Welte T, Polverino E, De Soyza A, Greville H, O’Donnell A, et al. Ciprofloxacin dry powder for inhalation in non-cystic fibrosis bronchiectasis: a phase II randomised study. Eur Respir J 2013;41(5): 1107-1115

16. Tsang KW, Ho PL, Lam WK, Ip MS, Chan KN, Ho CS, et al. Inhaled fluticasone reduces sputum inflammatory indices in severe bronchiectasis. Am J Respir Crit Care Med 1998;158(3):723-727.

17. Lavery K, O’Neill B, Elborn JS, Reilly J, Bradley JM. Self-management in bronchiectasis: the patient's perspective. Eur Respir J 2007; 29(3):541-547.

18. McCullough AR, Tunney MM, Elborn JS, Bradley JM, Hughes CM. 'All illness is personal to that individual': a qualitative study of patients' perspectives on treatment adherence in bronchiectasis. Health Expect 2015;18(6):2477-2488. 


\section{Health Perception and Behavior in Bronchiectasis}

19. Dudgeon EK, Crichton M, Chalmers JD. "The missing ingredient": the patient perspective of health related quality of life in bronchiectasis: a qualitative study. BMC Pulm Med 2018;18(1):81.

20. Hester KLM, Newton J, Rapley T, De Soyza A. Patient information, education and self-management in bronchiectasis: facilitating improvements to optimise health outcomes. BMC Pulm Med 2018;18(1):80.

21. Zhang ZM, Ren PH, Guan WJ. Symptom-based treatment with traditional Chinese medicine in bronchiectasis patients with hemoptysis. J Thorac Dis 2017;9(9):E884-E886.

22. Marteau T. Health beliefs and attributions. In: Broome A, Llewelyn S., editors. Health psychology, process and applications. 2nd ed. London: Chapman and Hall; 1995:3-20.
23. Guan WJ, Huang Y, Chen CL, Chen RC, Zhong NS. Macrolides, mucoactive drugs and adherence for the management of bronchiectasis. Eur Respir J 2018;51(1): pii: 1701987.

24. Aliberti S, Masefield S, Polverino E, De Soyza A, Loebinger MR, Menendez R, et al; EMBARC Study Group. Research priorities in bronchiectasis: a consensus statement from the EMBARC Clinical Research Collaboration. Eur Respir J 2016;48(3):632-647.

25. Guan WJ, Gao YH, Yuan JJ, Chen RC, Zhong NS. Additional important research priorities for bronchiectasis in China. Eur Respir J 2017;49(1): pii: 1601747.

26. Spinou A, Patel A, Garrod R, Caroline E, Loebinger M, Wilson R, et al. Understanding patients' experience of living with non-cystic fibrosis bronchiectasis. Eur Respir J 2013;42(Suppl 57): 1359. 